\title{
Interleukin-1 Induces Substance P in Sympathetic Ganglia through the Induction of Leukemia Inhibitory Factor (LIF)
}

\author{
Annette M. Shadiack, ${ }^{a}$ Ronald P. Hart, Christopher D. Carlson, and G. Miller Jonakait \\ Department of Biological Sciences, Rutgers University, Newark, New Jersey 07102
}

It has become increasingly clear that immune cytokines perform growth and differentiation functions in the nervous system similar to those performed in the immune system. In previous studies we have shown that interleukin-1 $\beta$ (IL-1 $\beta$ ) raises substance $P$ (SP) and the mRNA coding for its preprotachykinin precursor in cultured sympathetic superior cervical ganglia (SCG) (Jonakait and Schotland, 1990; Hart et al., 1991a). The action of IL-1 is blocked both by depolarization of the ganglia and by glucocorticoid hormones (Hart et al., 1991a). In the present report, we have found that IL-1 does not act directly upon neurons to raise SP, but rather induces the production of a soluble intermediate molecule that raises both SP and the cholinergic-specific enzyme ChAT. Its induction by IL- 1 is blocked by the synthetic glucocorticoid hormone dexamethasone; its action is compromised under depolarizing conditions.

Because medium conditioned by IL-1 (IL-1CM) is functionally similar to leukemia inhibitory factor (LIF), we sought to determine whether this molecule might be an active constituent of IL-1CM. Immunoprecipitation with an antiserum directed against LIF eliminated large proportions of SP-inducing activity from IL-1CM. In addition, steady-state levels of mRNA coding for LIF are increased by IL-1 treatment of SCG. These data suggest that LIF, induced by IL-1, may ultimately be responsible for the IL-1 induction of SP.

[Key words: substance $P$, interleukin-1, leukemia inhibitory factor, sympathetic ganglia]

A central issue of neuroscience concerns the mechanisms underlying the ability of the nervous system to respond to environmental stimuli that are both normal and traumatic. The nervous system maintains an extensive repertoire of adaptive responses to its environment; one that has been widely studied is the change in the biosynthesis of new neurotransmitter molecules.

The neonatal superior cervical ganglion (SCG) of the rat has been heavily scrutinized for its ability to alter its neurotransmitter complement in response to changing environmental signals (Johnson et al., 1976; Patterson and Chun, 1977; Kessler and Black, 1982; Kessler, 1984; see Jonakait and Black, 1989,

\footnotetext{
Received Oct. 8, 1992; revised Dec. 18, 1992; accepted Dec. 22, 1992.

We thank Dr. Li Ni for his help in performing ChAI assays. This research has been supported by the Office of Naval Research (N00014-90-J-1896) and by U.S. Public Health Service Grants RR 07059-24 (G.M.J.) and MH-00855 (R.P.H.).

Correspondence should be addressed to Dr. G. Miller Jonakait, Department of Biological Sciences, Rutgers University, 101 Warren Street, Newark, NJ 07102.

-Present address: Department of Neuroscience, Case Western Reserve University School of Medicinc, 10900 Euclid Avenue, Cleveland, OH 44106.

Copyright (c) 1993 Society for Neuroscience $0270-6474 / 93 / 132601-09 \$ 05.00 / 0$
}

for review). In one instance of dramatic neurotransmitter plasticity, substance P (SP) and the mRNA coding for its prohormone precursor are increased in response to ganglion deafferentation (Kessler et al., 1981; Roach et al., 1987). The functional significance of this increase and the mechanisms underlying it have been unclear. However, since the increase in SP occurs in the face of damage to the ganglion, we sought to determine whether immune cytokines, released during such an injury, played a role in regulating the increase in SP.

In recent studies designed to test the role of immune cytokines in $\mathrm{SCG}$ responsiveness, we and others have found that interleukin-1 $\beta$ (IL-1 $\beta$ ) elicits a dramatic increase in SP-like immunoreactivity and in the mRNA coding for its preprotachykinin prohormone precursor in cultured neonatal SCG (Jonakait and Schotland, 1990; Jonakait et al., 1990; Freidin and Kessler, 1991; Hart et al., 1991a). The ability of the ganglion to respond to IL-1 depends upon the absence of preganglionic electrical activity since mimicking presynaptic input prevents the IL-1induced ganglionic increase of SP (Hart et al., 199 1a). Moreover, glucocorticoid hormones, known to truncate the immune response in a variety of settings, blunt the ganglionic response to IL-1 as well (Hart et al., 1991a).

While IL- 1 induces SP in both explanted and dissociated SCG (Jonakait and Schotland, 1990; Freidin and Kessler, 1991), it fails to induce SP in neuronal cultures that lack non-neuronal cells (Freidin and Kessler, 1991). The requirement for nonneuronal cells implies either that non-neuronal cells "enable" neuronal responsiveness, or altematively, that non-neuronal cells, stimulated by IL-1, produce an intermediate molecule(s) that then stimulates neurons to produce SP.

While never localized within the SCG, leukemia inhibitory factor [LIF; also known as cholinergic differentiation factor; Johnson et al., 1976; Patterson and Chun, 1977; Fukada, 1985; Yamamori et al., 1990] promotes SP expression in SCG culturcs (Nawa and Sah, 1990; Kessler and Freidin, 1991; Rao et al., 1992). Therefore, LIF suggested itself as a candidate for a possible molecular intermcdiate. In this study, we have confirmed that IL-1 does not act directly on neurons to increase SP, and have found further that LIF is at least one of the molecular intermediates that promotes SP expression.

\section{Materials and Methods}

Cultures of superior cervical ganglia. Superior cervical (sympathetic) ganglia (SCG) from 1-d-old rat pups were cultured either as explants or as dissociated cells. Explanted SCG were plated in $35 \mathrm{~mm}$ culture dishes coated with rat tail collagen. The medium contained Ham's F12 medium with $10 \%$ heat-inactivated fetal calf serum (F12/FCS10) supplemented with $50-100 \mathrm{ng} / \mathrm{ml} 7 \mathrm{~S} \mathrm{NGF,} 100 \mathrm{U} / \mathrm{ml}$ penicillin, and $100 \mu \mathrm{g} / \mathrm{ml}$ streptomycin. Cultures were grown at $37^{\circ} \mathrm{C}$ in an atmosphere of $5 \% \mathrm{CO}_{2}$, 
and $100 \%$ humidity. When included, IL- $1 \beta(1 \mathrm{ng} / \mathrm{ml})$ was added at explantation.

For dissociated cultures, SCG were stripped of their connective tissue capsules and cleaned of residual blood. They were incubated in $0.25 \%$ trypsin in phosphate-buffered saline (PBS) for $45 \mathrm{~min}$ at $37^{\circ} \mathrm{C}$ and then dissociated by gentle trituration. The cells were counted and plated at a density of 1 SCG/dish (approximately $1.25 \times 10^{3} \mathrm{cells} /$ dish) in $\mathrm{F} 12 /$ FCS 10 medium supplemented with $50 \mathrm{ng} / \mathrm{ml} 2.5 \mathrm{~S} \mathrm{NGF}, 100 \mathrm{U} / \mathrm{m}$ penicillin, and $100 \mu \mathrm{g} / \mathrm{ml}$ streptomycin. Cells were fed cvery $2-3 \mathrm{~d}$ and remained in culture $8-10 \mathrm{~d}$. When included. human recombinant IL$1 \beta(\mathrm{hrlL}-1 \beta ; 1 \mathrm{ng} / \mathrm{ml})$ was added $48 \mathrm{hr}$ after plating.

In order to produce "pure" neuronal cultures, dissociatcd SCG cultures were prepared as described above. Dividing non-neuronal cells were killed by the addition of $10 \mu \mathrm{M}$ cytosine $\beta$-D-arabinofuranoside after 1 and $2 \mathrm{~d}$ in culture. Examination of the cultures using a phasecontrast microscope revealed them to be virtually free of non-ncuronal cells.

Preparation of $I L-1$-conditioned medium (IL-ICM). Ten to fifteen SCG were explanted in $35 \mathrm{~mm}$ dishes containing $1.5 \mathrm{ml}$ of F12/FCS10 as described above. In some cases, ganglia were explanted in reduced serum medium (Opti-MEM, GIBCO) containing an N2 supplement (GIBCO, N2 medium). Medium was harvested after 4-5 d and stored at $4^{\circ} \mathrm{C}$ until further use. Two SCG per dish were harvested for SP radioimmunoassay (RIA) (see below). When IL-I-conditioned medium (IL-ICM) was tested on explant cultures, SCG were grown singly (one per well) in uncoated 96-well tissue culture plates or five per well in 24well collagen-coated dishes. In each case, SCG were grown in a ratio of $100 \mu$ of IL-ICM per SCG. IL- ICM was filter sterilized $(0.22 \mu \mathrm{m}$ Millex filter, Millipore Corp.) before use on naive cultures.

Immunoprecipitation. IL-1CM was incubated for $1 \mathrm{hr}$ at $37^{\circ} \mathrm{C}$ with polyclonal antibodies raised against LIF. The antibody against LIF (1: 50) was raised against a 10 amino acid synthetic peptide found at the amino terminal end of LIF (Yamamori et al., 1990). Preimmune serum served as a control. Protein A-conjugated sepharose beads (Sepharose 4B Fast, Sigma) were added to the medium and incubated for $1 \mathrm{hr}$ with mixing. The slurry was microcentrifuged for $5 \mathrm{sec}$ and the supernatant removed and filter sterilized.

$S P$ RIA. SP RIA was performed as described previously (Jonakait and Schotland, 1990) using a rabbit polyclonal antibody specific for SP. The linear range of the assay (between 2 and $50 \mathrm{pg}$ ) necessitated the use of diluted samples when performing the RIA.

Choline acetyltransferase (ChAT) assay. ChAT was determined using the method of Fonnum (Fonnum, 1975) as modified by Martinez ct al. (1985).

Reverse transcription-polymerase chain reaction $(R T-P C R)$. Total cellular RNA was prepared by the guanidinium-acid phenol method (Chomczynski and Sacchi, 1987), modified as described (Hart et al., $1991 \mathrm{~b}$ ). One microgram of RNA was reverse transcribed to cDNA in a $30 \mu l$ reaction [containing $50 \mathrm{~mm}$ Tris- $\mathrm{HCl}(\mathrm{pH} 8.3), 75 \mathrm{~mm} \mathrm{KCl}, 3$ $\mathrm{mm} \mathrm{MgCl}_{2}, 0.1 \mathrm{mg} / \mathrm{ml} \mathrm{BSA}, 40 \mathrm{U}$ R Nasin (Promcga), $3 \mathrm{~mm}$ random hexamer primers (Promega), $0.5 \mathrm{~mm}$ each deoxynucleotide triphosphate and $10 \mathrm{U} / \mu \mathrm{l} \mathrm{M}-\mathrm{MLV}$ reverse transcriptase (GIBCO/Bethesda Research Laboratories)] for $1 \mathrm{hr}$ at $42^{\circ} \mathrm{C}$. A $5 \mu \mathrm{l}$ aliquot was amplified by PCR in a $50 \mu \mathrm{l}$ reaction containing $0.2 \mathrm{~mm}$ concentrations of each deoxynucleotide triphosphate, $50 \mathrm{~mm}$ Tris- $\mathrm{HCl}(\mathrm{pH} 9.0), 1.5 \mathrm{~mm} \mathrm{MgCl}_{2}, 20 \mathrm{~mm}$ $\left(\mathrm{NH}_{4}\right)_{2} \mathrm{SO}_{4}, 1 \mu \mathrm{M}$ concentrations of each oligonucleotide primer, $10 \mu \mathrm{Ci}$ of $\alpha^{-32} \mathrm{P}-\mathrm{dATP}$, and $1 \mathrm{U}$ of Pyrostase polymerase (Molecular Genetic Resources, Tampa, FL). The PCR reaction was processed in a PerkinElmer-Cetus thermocycler programmed to the following conditions: $94^{\circ} \mathrm{C}$ $30 \mathrm{sec}, 60^{\circ} \mathrm{C} 30 \mathrm{sec}$, and $72^{\circ} \mathrm{C} 1 \mathrm{~min}$. Aliquots were removed at three successive cycles (the number of cycles to be used for quantitation was empirically determined by plotting a wider range of cycle aliquots and locating the range of detectable, constantly logarithmic amplification). The aliquots were electrophoresed on a $6 \%$ nondenaturing acrylamide gel that was then dried and autoradiographed. Individual gel bands were located by aligning with film, excised, and quantified by Cerenkov counting.

The LIF primers (LIF-1: 5'CCCCTACTGCTCATTCTGCACTGG; LIF-2: 5'TGCTAAGGAGCCCCCTCATGACGT) were characterized by sequencing a sample cDNA product to determine its identity with published rat LIF sequence (Yamamori et al., 1990; C.-L. Liu, unpublished observations). For each RNA sample tested, parallel PCR reactions were run with a "control" set of primers, such as rat cytoplasmic actin (Nudel ct al., 1983). The relative level of specific mRNA was expressed as a ratio of cpm specific LIF PCR product to $\mathrm{cpm}$ cytoplasmic actin PCR product. This method has been used with other primers in our laboratory (Hart et al., 1993).

In test experiments with other PCR primers (not shown), the quantitative reverse transcription-PCR (RT-PCR) reaction in our laboratory has successfully detected differences as small as $10 \%$ in a statistically significant fashion (measured by analysis of variance; $95 \%$ confidence limits were established using the Fisher test).

Materials. Murine NGF, both 7S and 2.5S, were gifts from Michael Coughlin, McMaster University. SP antibody was a gift from Susan Lecman, Boston University School of Medicine. Antiserum to cholinergic differentiation factor (LIF) was a gift from Paul Patterson, California Institute of Technology. Recombinant IL-1 receptor antagonist was a gift from Synergen (Boulder, CO). Human recombinant IL-1B was a gift from Lederle Labs (Pearl River, NY). Murine recombinant LIF (mrLIF) was purchased from Amrad (Kew, Victoria, Australia).

\section{Results}

The action of $I L-1$ is medialed by an intermediate molecule

In order to test whether IL-1 stimulated the production of a molecular intermediate, medium conditioned by IL-1 (IL-1CM) was tested for its effects on SP expression.

Conditioned medium (CM) was obtained by culturing 10-15 ganglia for 4-5 $\mathrm{d}$ in the presence or absence of IL- $1 \beta$ (see Materials and Methods). Ganglia harvested at the end of this initial culture period revealed the efficacy of IL-1 in raising SP (Fig. 1). Control CM and IL-1CM were then added to a naive set of SCG. To ensure that the increase in SP in the IL-1CM-treated cultures was not due to residual IL-1, a specific IL-1 receptor antagonist (IL- $1 \mathrm{ra} ; 200 \mathrm{ng} / \mathrm{ml}$; Hannum et al., 1990) was added to the CM. In other experiments, this antagonist inhibited the IL-1-induced increase in SP by $50 \%$ (Hart et al., 1993).

CM from IL-1-treated cultures significantly raised SP in naive SCG (Fig. 1). IL-1 ra did not inhibit the IL-1CM-induced increase, suggesting that the increase in SP was not due to residual IL-1, but rather was due to an intermediate molecule induced by IL-1. A dose-response analysis of IL-1CM showed that a half-maximal response occurred at about a 10-fold dilution, while concentrations greater than $25 \%$ produced maximal SP production (Fig. 2). A 32-fold dilution was nccessary before IL$1 \mathrm{CM}$ achieved SP levels equivalent to those obtained with control (uninduced) $\mathrm{CM}$.

Interestingly, levels of SP present in ganglia treated with control CM were significantly lowered by the IL-1 ra (Fig. 1). This suggests that cultured ganglia produce low levels of IL-1-possibly neuronal in origin (Schultzberg et al., 1987; Freidin et al., 1992; A. M. Shadiack, R. P. Hart, C. D. Carlson, and G. M. Jonakait, unpublished observations).

\section{IL-ICM elevates SP in both mixed dissociate and pure neuronal cultures}

Consistent with the reports of others (Freidin and Kessler, 1991), we found that IL-1 raised SP above control levels in cultures comprising both neurons and non-neuronal cells (mixed dissociates; Fig. 3). In mixed dissociates, IL-ICM was strikingly more potent than IL- 1 itself in raising SP.

Pure neuronal cultures exposed to IL-1 showed no increase in SP levels (sce also Freidin and Kessler, 1991). However, IL$1 \mathrm{CM}$ produced a dramatic increase in SP (Fig. 3). In pure neuronal cultures, IL-1CM raised SP significantly at dilutions as high as $1: 10$ (data not shown). The induction of SP by IL-1CM but not by IL- 1 confirms that the active molecule in IL-1CM is different from IL-1 itself.

We can conclude, then, that while IL-1 itself does not act 

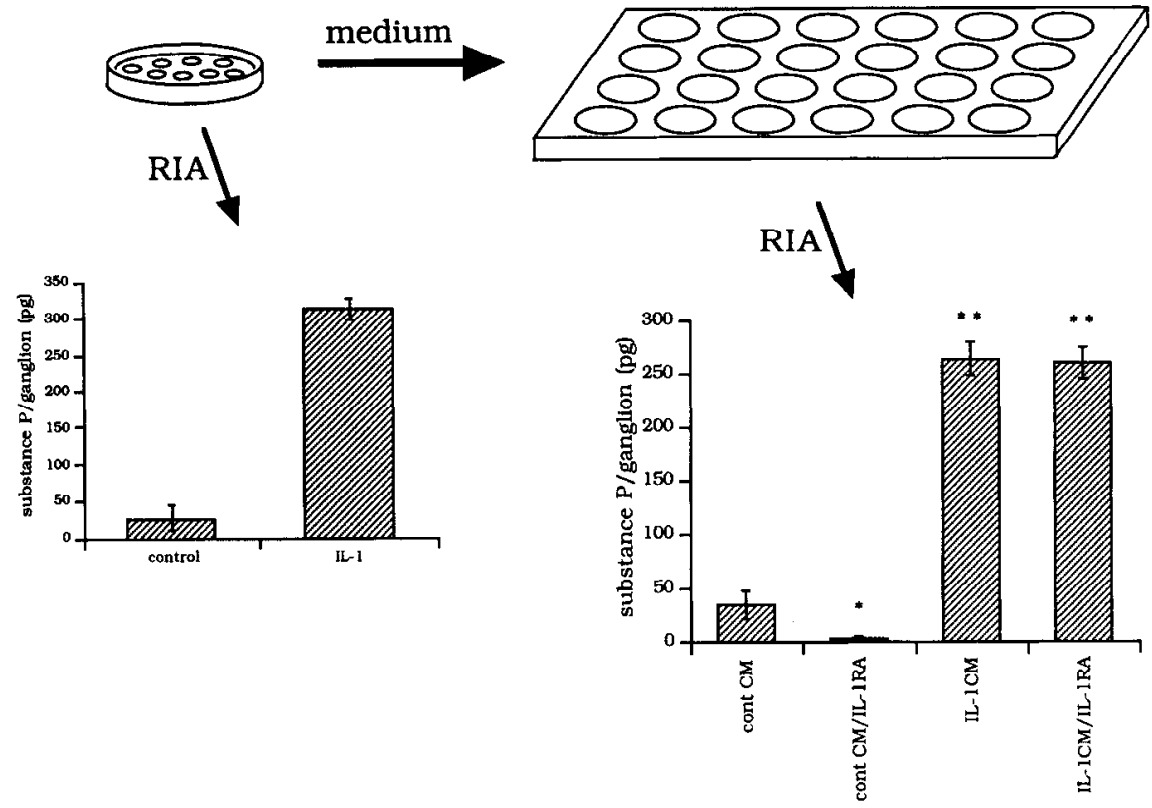

Figure 1. IL-1CM effects on SP expression. Explant cultures were grown 10 per dish in medium with or without $1 \mathrm{ng} / \mathrm{ml} \mathrm{hrIL-1 \beta}$ (see Materials and Methods). Two representative explants per dish were assayed for SP by RIA to ensure SP induction had occurred (left graph). IL-CM or control CM (cont CM) with and without IL-1 ra $(200 \mathrm{ng} / \mathrm{ml})$ was then added to a naive set of ganglia and SP was assayed after $4 \mathrm{~d}$ (right graph). Each bar represents the mean \pm SEM of five or six ganglia. Data were compared by a two-tailed Student's $t$ test. ${ }^{*}, p<0.06$ compared to cont $C M$ ${ }^{* *}, p<0.0001$ compared to cont $C M$.

upon neurons to raise SP, it induces the production of a soluble molecular intermediate that is capable of inducing neuronal SP.

\section{Characterization of the intermediate molecule(s)}

In order to determine whether the intermediate was protein in nature, we tested the effects of boiling on its activity. Ganglia were grown in N2-supplemented medium (see Materials and Methods) with or without IL-1. Control CM and IL-1CM were boiled for $30 \mathrm{~min}$, filter sterilized, and resupplemented with N2 (GIBCO) and 7S NGF before being added to naive ganglia. Boiling severely reduced the ability of $I L-1 C M$ to raise SP in SCG explants (data not shown), suggesting that the active factor in IL-1CM was proteinaceous. Fresh IL-1 added after boiling elevated SP in a naive set of explants, thereby establishing that boiling the medium had not compromised the survival or responsiveness of the explants (data not shown).

In order to obtain an estimate of the size of the active IL$1 \mathrm{CM}$ molecule(s), ganglia were again cultured in N2 medium

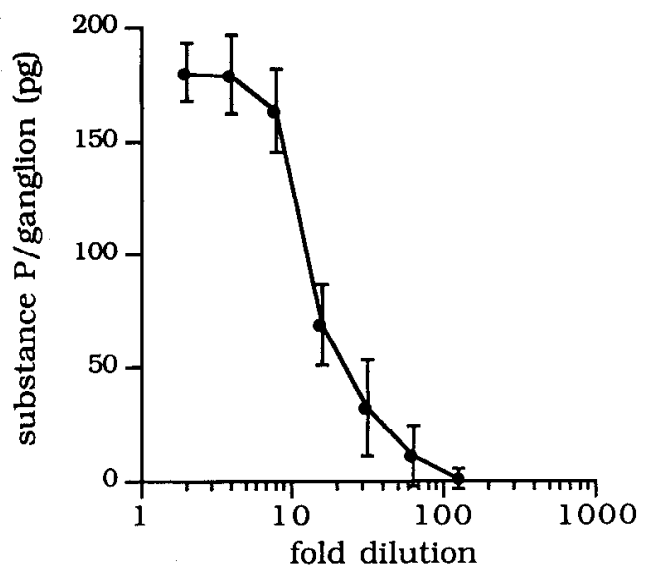

Figure 2. IL-1CM dose-response on SP expression in explants. Explant cultures were treated with IL-1CM, diluted as indicated. In sister cultures, control CM induced $35.9 \pm 12.6 \mathrm{pg}$ of SP/ganglion. Each point represents the mean \pm SEM of five or six ganglia. with and without IL-1. IL-1CM was fractionated using Centricon filters (Amicon Corp., Beverly, MA). The IL-1CM was passed through a Centricon-30 filter with 10 sample volumes. The dialysate was then passed through a Centricon-10 filter and centrifuged until the original volume was achieved. Unfractionated IL-1CM as well as the three fractions resulting from this procedure were tested for SP-inducing activity. All samples were diluted 10-fold. SP-inducing activity was equally distributed between the $10-30 \mathrm{kDa}$ and the $>30 \mathrm{kDa}$ fractions (Fig. 4). No activity appeared in the $<10 \mathrm{kDa}$ fraction. IL- 1 ra treatment of these fractions significantly depleted the $10-30 \mathrm{kDa}$ fraction but had little effect on the $>30 \mathrm{kDa}$ fraction, which retained most of its activity (data not shown). These data suggested that activity in the $10-30 \mathrm{kDa}$ fraction could be ascribed to residual IL-1 $\left(M_{r}=17,500\right)$ while the active SP-inducing intermediate had a molecular weight greater than $30 \mathrm{kDa}$.

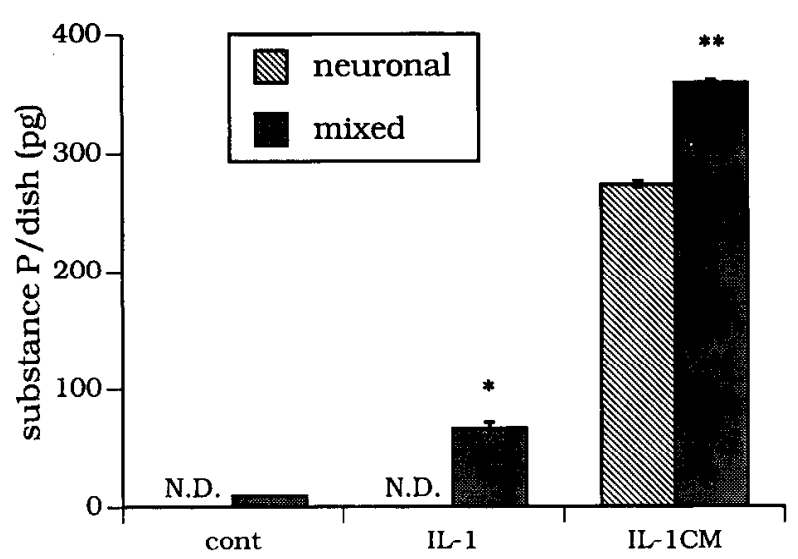

Figure 3. Effects of IL-1 and IL-1CM on SP expression in mixed and neuronal cultures. Mixed or pure neuronal dissociated SCG cultures were treated with medium alone (cont), medium containing $1 \mathrm{ng} / \mathrm{ml}$ hrIL-1, or IL-1CM diluted fivefold. Each bar represents the mean \pm SEM of four dishes. N.D., not detected. An ANOVA followed by Fisher's test showed groups that were statistically different from each other at $95 \%$ confidence limits. ${ }^{*}$, different from IL-1 (neuronal); ${ }^{* *}$, different from IL-1 (mixed) and different from IL-1CM (neuronal). 


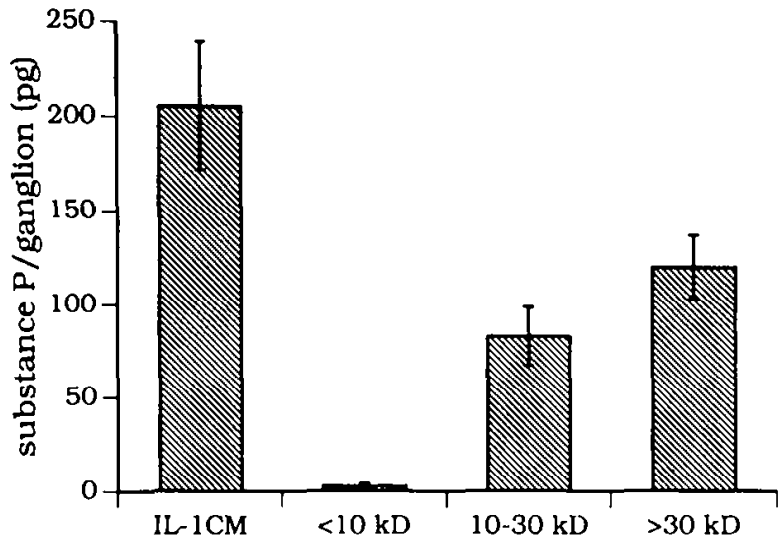

Figure 4. SP-inducing activity in fractionated IL-1CM. Explant cultures were treated with IL-ICM prepared in reduced serum medium (N2). IL-ICM was fractionated as described in Results. IL-1CM and fractionated IL-1CM were diluted 10-fold before being added to SCG explants. Each bar represents the mean \pm SEM of five or six ganglia.

\section{Depolarization blocks the action, not the production, of} $I L-I C M$

Whife depolarization blocks the ability of the ganglion to respond to IL-1 (Hart et al., 1991a), it was unclear whether depolarization blocked the production of the molecular intermediate(s) or whether it inhibited the action of these molecules on the induction of SP. In order to distinguish between these two altcrnatives, wc preparcd IL-ICM in the presence and absence of $20 \mu \mathrm{M}$ veratrine. Subsequent dialysis of the IL-1CM reduced the concentration of veratrine to approximately $3 \mu \mathrm{M}$. Further dilution of the dialysed IL-ICM resulted in negligible concentrations of veratrine (approximately $0.4 \mu \mathrm{M}$ ). IL-1CM prepared in the presence of veratrine raised SP well above control $C M$ and even higher than with IL-1CM alone (Fig. 5A). These data suggest that, far from inhibiting the production of IL-ICM, depolarizing agents actually enhance the IL-1-induced production of the SP-inducing intermediate. Positive effects of depolarization on the elaboration of growth-and survival-promoting factors have been noted by others (Brenneman et al., 1984; Cohen-Cory et al., 1991).

Explants treated with IL-ICM in the presence of $20 \mu \mathrm{M}$ veratrine failed to show elevated SP (data not shown). However, since veratrine may be neurotoxic at high concentrations (Sun et al., 1992), we cultured SCG explants with IL-1CM using 40 $\mathrm{mM} \mathrm{KCl}$ as an alternative effector of depolarization. The action of IL-1CM in the presence of $\mathrm{KCl}$ was dose dependent: IL-ICM used at full strength was not affected by $40 \mathrm{~mm} \mathrm{KCl}$, while IL$1 C M$ diluted 10 -fold was substantially inhibited (Fig. $5 B$ ).

These data taken together suggest that depolarization inhibits the IL-1 induction of SP not by inhibiting the production of the molecular intermediate(s), but rather by inhibiting the action of that intermediate on the neuron.

\section{Dexamethasone blocks the production, not the action, of $I L-I C M$}

In previous experiments, we had shown that the synthetic glucocorticoid hormone dexamethasone (DEX) completely inhibits the IL-1 induction of SP (Hart et al., 1991a). In order to determine whether DEX blocked the action of IL-ICM on SP induction, pure neuronal cultures were treated with IL-1CM and $0.01 \mu \mathrm{M}$ DEX. By itself, DEX had no effect on SP induction
A

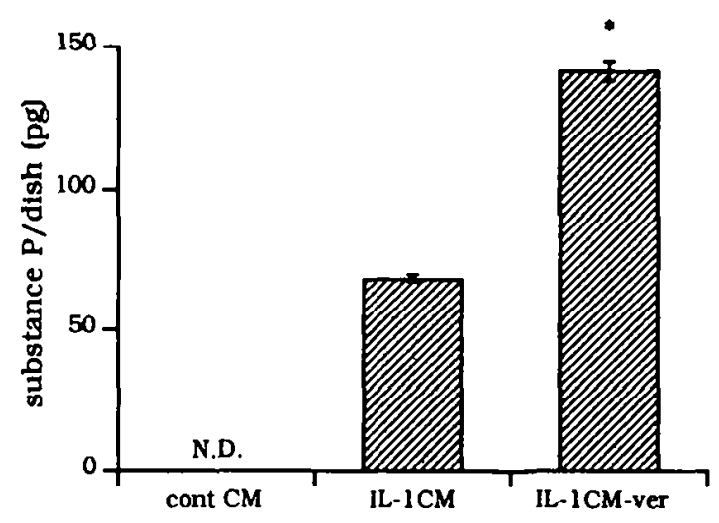

B

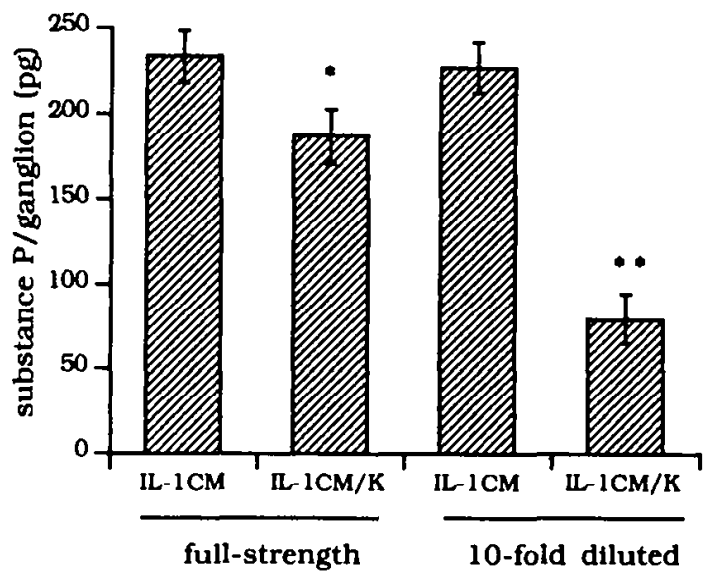

Figure 5. Effects of depolarization on the production $(A)$ and action $(B)$ of IL-ICM. $A$, SP was assayed in neuronal dissociate SCG cultures treated with cither $15 \%$ IL-ICM or $15 \%$ IL-1CM raised in the presence of $20 \mu \mathrm{M}$ veratrine $(I L-I C M$-ver). Veratrine in the IL-ICM was removed by dialysis and subsequent dilution (see text). Fach bar represents the mean \pm SEM of four dishes. * $p<0.0001$ compared with IL-1CM. $B, \mathrm{SP}$ immunoreactivity was assayed in explant cultures treated with $(I L-I C M / K)$ or without $(I L-I C M) 40 \mathrm{mM} \mathrm{KCl}$ in IL- $1 \mathrm{CM}$ at full strength or diluted 10-fold. *, $p<0.07$ compared with IL-1CM (full-strength). **, $p<0.0001$ compared with IL-1CM (10-fold diluted).

while IL-1CM produced its expected effect (Fig. 6A). However, DEX failed to block the action of IL-ICM, suggesting that glucocorticoids do not block the action of the intermediate.

However, DEX $(0.01 \mu \mathrm{M})$ completely blocked the production of IL-1CM in IL-1-treated explants: IL-1CM, produced in the presence of DEX, was unable to alter SP expression in pure neuronal cultures, while IL-1CM prepared from sister cultures in the absence of DEX raised SP well above control (Fig. 6B). The DEX concentration was reduced to approximately $0.2 \mathrm{~nm}$ after dialysis and dilution. In addition, however, DEX had no effect on SP induction in neurons (see Fig. 6A). These data suggest that the action of DEX in the inhibition of the IL-1 induction of SP is to block of the production of the intermediate molecule(s). 
A

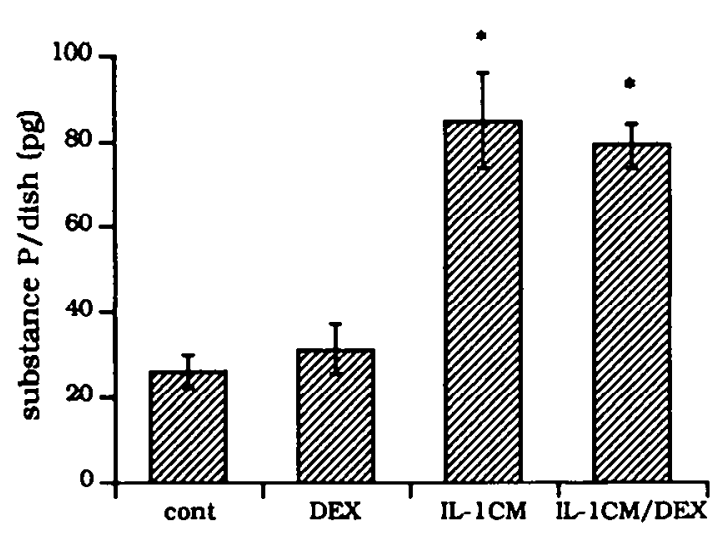

B

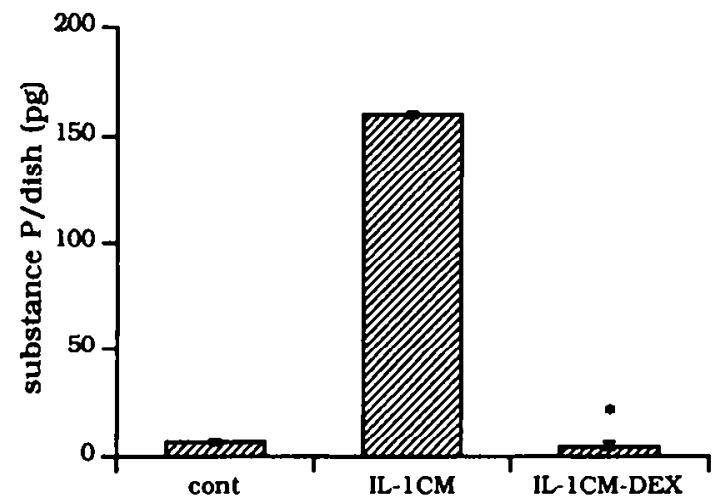

Figure 6. Effects of DEX on SP induction by IL-ICM $(A)$ and production of IL-ICM $(B)$. A, Pure neuronal dissociate SCG cultures were treated with medium only (cont), $0.01 \mu \mathrm{M}$ DEX, or $20 \%$ IL-1CM in the presence or absence of $0.01 \mu \mathrm{M}$ DEX. ${ }^{*}, p<0.005$ compared with cont or DEX. $B$, Neuronal dissociate SCG cultures were treated with control CM (cont), or with $15 \% \mathrm{IL}-1 \mathrm{CM}$ prepared in reduced serum medium (N2) in the presence (IL-ICM-DEX) or absence $(I L-I C M)$ of $0.01 \mu \mathrm{M}$ DEX. ${ }^{*}, p<0.0001$ compared with IL-ICM.

\section{IL-ICM increases ChAT activity}

Since LIF is known to induce SP in cultured SCG (Nawa and Patterson, 1990; Nawa and Sah, 1990; Kessler and Freidin, 1991), it presented itself as a possible candidate for the active factor in IL-1CM. Since LIF also induces cholinergic characteristics in cultured sympathetic ganglion cells (Yamamori et al., 1990), then if LIF were the active factor in the IL-1CM, IL$1 \mathrm{CM}$ should induce the cholinergic phenotype as well. We therefore measured ChAT activity as one index of cholinergic expression. In explant cultures, IL-1, mrLIF (murine recombinant LIF), and IL-ICM all increased ChAT activity significantly above control (Fig. $7 A$ ), suggesting a common spectrum of action.

As reported by others (Nawa and Patterson, 1990; Kessler and Freidin, 1991), LIF also raises ChAT activity in pure neuronal cultures. We therefore compared the abilities of IL-1 and IL-ICM to raise ChAT in pure neuronal cultures (Fig. $7 B$ ). Similar to its mode of action on SP, IL-1 failed to raise ChAT in the absence of non-neuronal cells. IL-ICM, on the other hand,
A

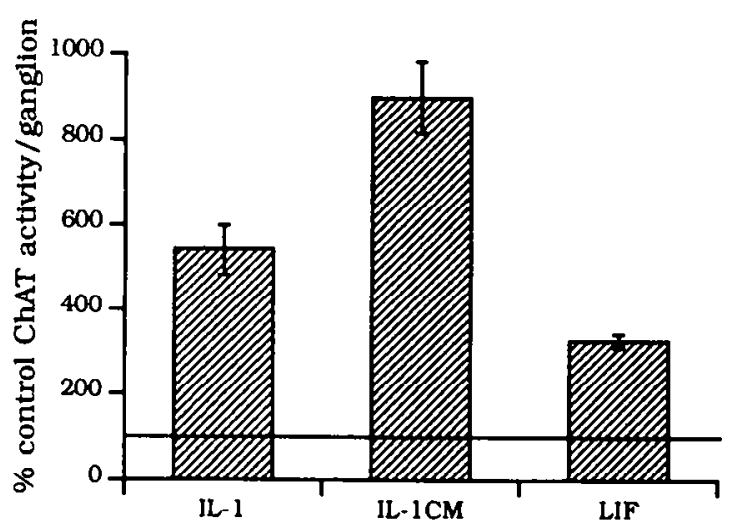

B

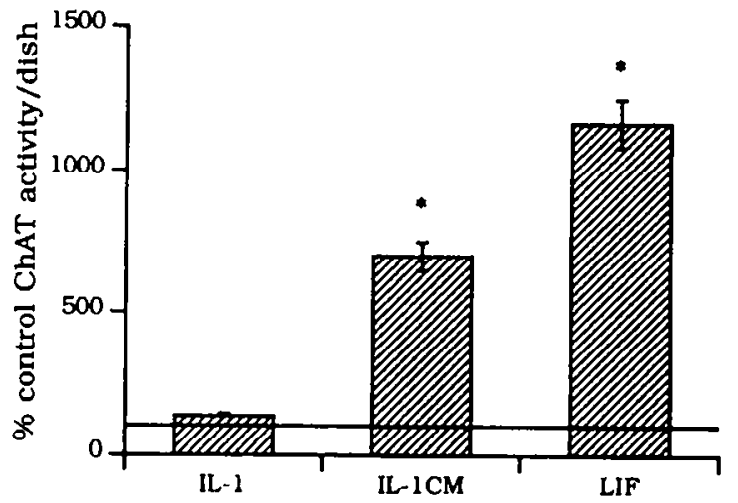

Figure 7. Effects of IL-1, IL-1CM, and LIF on ChAT activity in explants $(A)$ and pure neuronal dissociates $(B)$. Explant cultures were treated with medium only, $10 \mathrm{ng} / \mathrm{ml}$ hrIL-1, $50 \% \mathrm{IL}-1 \mathrm{CM}$, or $1000 \mathrm{U} /$ $\mathrm{ml}$ LIF. Neuronal dissociate SCG cultures were treated similarly except that $20 \%$ IL-1CM was used. Data arc expressed as percentage of control ChAT activity (line). Each bar represents the mean \pm SEM of four dishes. ${ }^{*}, p<0.0003$ compared with control.

dramatically elevated ChAT activity in pure neuronal cultures, confirming a second action common to both IL-1CM and LIF.

\section{Glucocorticoid hormones do not affect LIF activity}

DEX does not affect the ability of IL-1CM to raise SP (see above). Therefore, if LIF is the active molecule in IL-1CM, then DEX should not affect the SP-inducing activity of LIF. DEX failed to alter the levels of SP induced by LIF in pure neuronal dissociates (data not shown), suggesting another similarity between IL-1CM and LIF.

\section{Immunoprecipitation of $L I F$ from $I L-I C M$ reduces $S P$-inducing activity}

In order to determine whether LIF is a constituent of IL-1CM, IL-1CM was immunoprecipitated either with LIF antiserum or with prcimmune serum (see Materials and Methods). This antiserum immunoprecipitates cholinergic differentiating activity from heart cell-conditioned medium (Yamamori et al., 1990) and immunoprecipitates the SP-inducing activity of authentic 
$\mathbf{A}$

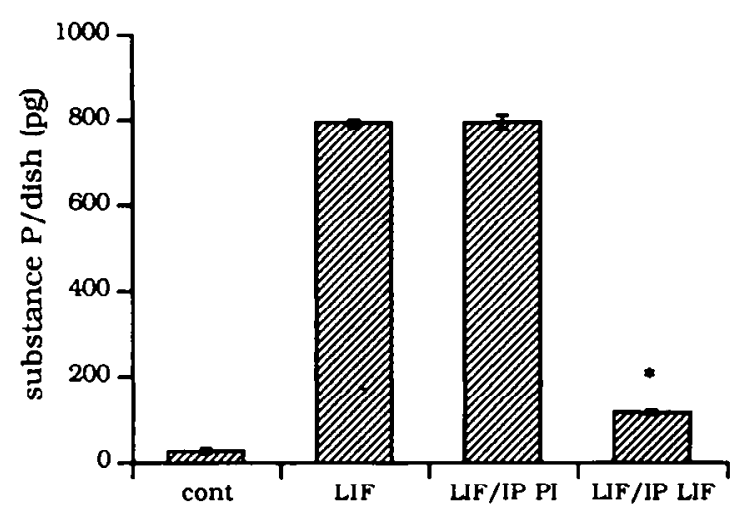

B

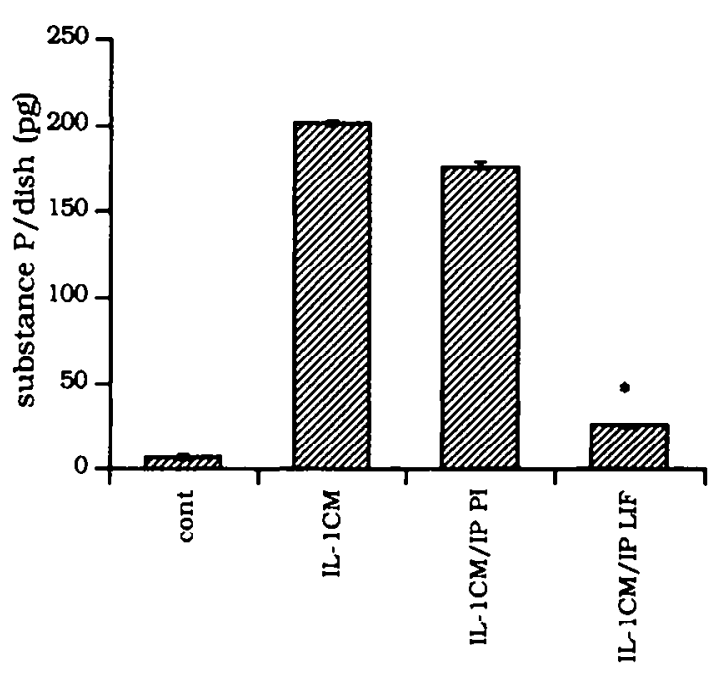

Figure 8. Immunoprecipitation of SP-inducing activity from LIF- and IL-1CM-containing medium. Medium containing $500 \mathrm{U} / \mathrm{ml} \mathrm{mrLIF}(A)$ or $16 \%$ IL- $1 \mathrm{CM}(B)$ was immunoprecipitated $(I P)$ with preimmune serum $(/ I P P I)$ or LIF antiserum (/IP LIF), both diluted 1:50 before being added to neuronal dissociates. Each bar represents the mean \pm SEM of four dishes. $A:^{*}, p<0.0001$ compared to LIF/IP PI. $B:^{*}, p$ $<0.0001$ compared with IL-1CM/IP PI.

LIF in SCG cultures (Fig. 8A). Immunoprecipitation of the ILICM with LIF antiserum, but not with preimmune serum, dramatically and significantly reduced the ability of IL-ICM to induce SP in pure neuronal cultures (Fig. $8 B$ ), suggesting that LIF might be one of the active molecules in IL-ICM.

\section{LIF mRNA is induced in IL-I-treated cultures}

In order to determine whether LIF was produced in IL-1-treated cultures, RNA obtained from control and IL-1-treated explants was subjected to RT-PCR analysis using primers specific for rat LIF (see Materials and Methods). Freshly dissected ganglia had undetectable levels of LIF mRNA. After even a brief time in culture, low levels of the mRNA were evident. Treatment of the cultures with IL-1 dramatically increased the steady-state levels of LIF mRNA (Fig. 9). These data show directly that IL-1 induces LIF mRNA, making it likely that LIF is available in cultured ganglia to effect changes in SP expression.

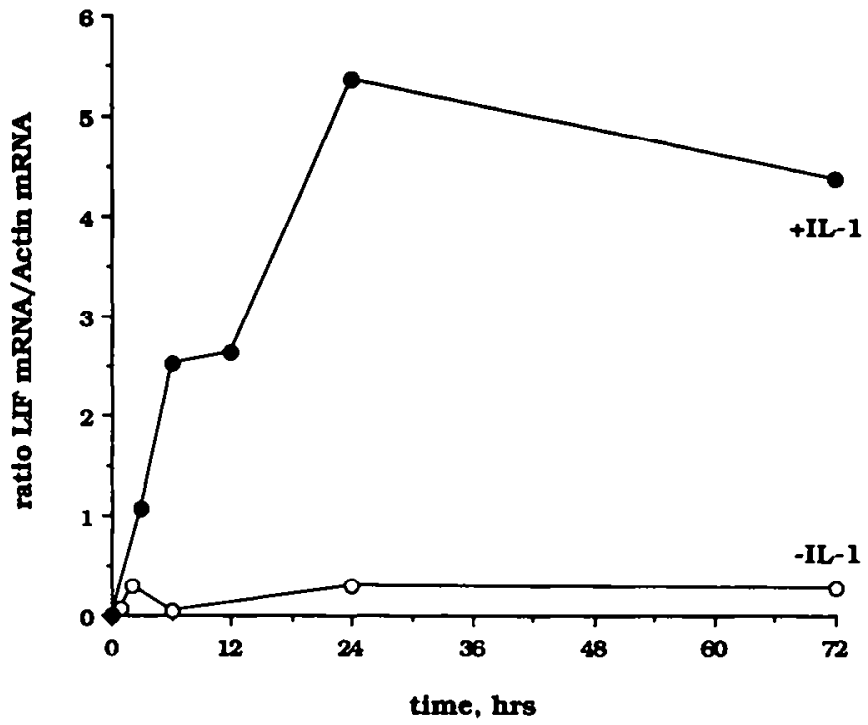

Figure 9. Time course of LIF mRNA induction in IL-1-treated SCG explant cultures. SCG were dissected and cultured in the presence or absence of $1 \mathrm{ng} / \mathrm{ml} \mathrm{IL-1 \beta}$. LIF mRNAs were measured by quantitative RT-PCR (see Materials and Methods) and expressed as a ratio to rat actin mRNA determined in parallel assays. Each point represents RNA pooled from a single group of 6-10 SCG. Two independent culture experiments were performed and assayed, producing similar results.

\section{Discussion}

It is by now abundantly clear that immune system cytokines are important mediators through which environmental signals are translated into neurobiological processes in general and neurotransmitter biosynthesis in particular. Molecules once thought to have actions restricted to the immune system are not only elaborated by the nervous system (Frei et al., 1985; Giulian et al., 1986; Tedeschi et al., 1986; Giulian and Ingeman, 1988; Hetier et al., 1988), but directly affect the proliferation (Fontana et al., 1980; Giulian and Baker, 1985; Giulian and Lachman, 1985; Benveniste and Merrill, 1986; Saneto et al., 1986), survival (Larsson et al., 1989; Chang et al., 1990), neurite outgrowth (Kamegai et al., 1990), and neurotransmitter expression (Scarborough et al., 1989; Jonakait and Schotland, 1990; Jonakait et al., 1990; Yamamori et al., 1990; Hart et al., 1991a) of cells of the nervous system as well.

We (and others) have shown previously that IL-1 induces SP in cultured sympathetic ganglia (Jonakait and Schotland, 1990; Jonakait et al., 1990; Barbany et al., 1991; Freidin and Kessler, 1991; Hart et al., 1991a). We have now shown that the IL-1 induction of SP expression depends upon the IL-1 induction of soluble intermediates. These intermediates must derive from non-neuronal cells since IL-I is unable to induce SP in pure neuronal cultures. Since specific antibodies against LIF immunoprecipitate SP-inducing activity from IL-ICM, one of the IL-1-induced factors is immunologically similar to LIF. The identification of LIF as an active factor in IL-ICM is strengthened by its shared spectrum of action with IL-1CM: IL-1CM and LIF both raise SP levels and increase ChAT activity, both are inhibited by depolarizing stimuli (Rao et al., 1992), and DEX fails to affect their SP-inducing ability. Fractionation of IL-ICM shows that its activity is independent of IL-1, and its size ranges from $10-30 \mathrm{kDa}$ to over $30 \mathrm{kDa}$, further implicating LIF (45 kDa; Fukada, 1985). Finally, the induction by IL-1 of 
mRNA coding for LIF makes it highly likely that LIF is available in cultured ganglia to effect changes in SP expression.

While the full range of signal transduction from the IL-1 rcceptor is unknown, IL- 1 activation of the transcription factor $\mathrm{NF}-\mathrm{kB}$ is one possible means of effecting IL-1 action (Osborn et al., 1989; Nonaka and Huang, 1990; Aniswicz et al., 1991). An NF- $\mathrm{kB}$ response element sequence is present in the promoter region of murine LIF (Stahl et al., 1990).

The IL-1 induction of LIF has been reported in bone marrow (Wetzler et al., 1991). Moreover, it is reminiscent of the action of IL-1 in the induction of NGF following sciatic nerve lesion (Lindholm et al., 1987). In that instance, the induction by a cytokine of a growth factor required for maintenance and survival of injured neurons pointed to an important interaction between immune and nervous systems in recovery from injury.' However, in the present instance, the induction by a cytokine of a sympathetic neuron differentiation factor that raises both SP and ChAT not only emphasizes the interaction between immune and nervous systems, but also raises questions concerning the role(s) of both ACh and SP in recovery from ganglionic injury.

The upregulation of ChAT might be viewed simply as a homeostatic response by the ganglion to restore cholinergic presynaptic input destroyed by deafferentation and subsequent explantation into culture. Moreover, the role of SP in modulating sympathetic nicotinic receptor sensitivity in normal ganglia is well documented (Akasu et al., 1983; Role, 1984). However, its role in deafferented ganglia could extend beyond this function. For example, in CNS, at least, astrocytes express SP receptors both in culture (Torrens et al., 1989) and in vivo after injury (Mantyh et al., 1989). While the functional significance of upregulating SP receptors on astrocytes is not entirely clear, one role may be to augment the SP-induced release of prostaglandins (Marriott et al., 1991) or to augment $\beta$-adrenergic activation of astrocytes (Rougon et al., 1983). The role, if any, that SP may play in affecting Schwann cell metabolism in peripheral ganglia is, at this point, obscure.

The role of SP in stimulating immune function, however, is well documented (Bar-Shavit et al., 1980; Fewtrell et al., 1982; Payan et al., 1983; Stanisz et al., 1986; Matsuda et al., 1989; Moore et al., 1989; Muscettola and Grasso, 1990; Rameshwar et al., 1992). SP is present in fibers innervating the spleen, thymus, and lymph nodes (Felten et al., 1985; Fink and Weihe, 1988; Popper et al., 1988; Weihe et al., 1989; Kurkowski et al., 1990), and contacting mast cells in the intestine (Bienenstock ct al., 1987). While SP-positive nerve fibers have generally been thought to arise from sensory systems, sympathetic innervation of lymphoid organs is also well described (Felten et al., 1987; Maddens et al., 1989; Reder et al., 1989). If SP, elevated in sympathetic ganglia after deafferentation, is transported to these immune organs, it is anatomically poised to exert effects on the immune systcm. Current data suggest that this new pool of SP is not transported (at least to iris and pineal) (Kessler and Black, 1982), but direct data are lacking.

\section{References}

Akasu T, Kojima M, Koketsu K (1983) Substance P modulates the sensitivity of the nicotinic receptor in amphibian cholinergic transmission. Br J Pharmacol 80:123-131.

\footnotetext{
'In earlier studies, we determined that NGF did not mediate the SP-inducing activity of IL-1 (Jonakait and Schotland, 1990).
}

Aniswicz A, Messineo M, Lee SW, Sager R (1991) An NF-kB-like transcription factor mediates IL-1/TNF- $\alpha$ induction of gro in human fibroblasts. J Immunol 147:520-527.

Barbany G, Friedman WJ, Persson H (1991) Lymphocyte-mediated regulation of neurotransmitter gene expression in rat sympathetic ganglia. J Ncuroimmunol 32:97-104.

Bar-Shavit Z, Goldman R, Stabinsky Y, Gottleib P, Fridkin M, Teichbert VI, Blumberg S (1980) Enhancement of phagocytosis-a newly found activity of substance $P$ residing in its $N$-terminal tetrapeptide sequence. Biochem Biophys Res Commun 94:1445.

Benveniste EN, Merrill JE (1986) Stimulation of oligodendroglial proliferation and maturation by interleukin-2. Nature 321:610-613.

Bienenstock J, Tomioka M, Matsuda H, Stead RH, Quinonez G, Simon GT, Coughlin MD, Denburg JA (1987) The role of mast cells in inflammatory processes: evidence for nerve/mast cell interactions. Int Arch Allergy Appl Immunol 82:238-243.

Brenneman DE, Fitzgerald S, Nelson PG (1984) Interaction between trophic action and electrical activity in spinal cord cultures. Dev Brain Res 15:211-217.

Chang JY, Martin DP, Johnson EM Jr (1990) Interferon suppresses sympathetic neuronal cell death caused by nerve growth factor deprivation. J Neurochem 55:436-445.

Chomczynski P, Sacchi N (1987) Single-step method of RNA isolation by acid guanidinium thiocyanate-phenol-chloroform extraction. Anal Biochem 162:156-159.

Cohen-Cory S, Elliott RC, Dreyfus CF, Black IB (1991) Expression of the NGF receptor gene by cerebellar Purkinje neurons in culture is regulated by depolarizing influences. Soc Neurosci Abstr 17:929.

Felten DL, Felten SY, Carlson SL, Olschowka JA, Livnat S (1985) Noradrenergic and peptidergic innervation of lymphoid tissue. J Immunol 135:755s-765s.

Felten DL, Felten SY, Bellinger DL, Carlson SL, Ackerman KD, Madden KS, Olschowki JA, Livnat S (1987) Noradrenergic sympathetic neural interactions with the immune system: structure and function. Immunol Rev 100:225-258.

Fewtrell CMS, Foreman JC, Jordan CC, Oehme P, Renner H, Steward JM (1982) The effects of substance $P$ on histamine and 5-hydroxytryptamine release in the rat. J Physiol (Lond) 330:393411 .

Fink T, Weihe E (1988) Multiple neuropeptides in nerves supplying mammalian lymph nodes: messenger candidates for sensory and autonomic neuroimmunomodulation? Neurosci Lett 90:39-44.

Fonnum F (1975) Rapid radiochemical method for the determination of choline acetyltransferase. J Neurochem 24:403-407.

Fontana A, Grieder A, Arrenbrecht S, Grob PJ (1980) In vitro stimulation of glia cells by a lymphocyte-produced factor. J Neurol Sci 46:55-62.

Frei K, Bodmer S, Schwerdez C, Fontana A (1985) Astrocytes of the brain synthesize interleukin 3-like factors. J Immunol 135:4044-4047

Freidin M, Kessler JA (1991) Cytokine regulation of substance P expression in sympathetic neurons. Proc Natl Acad Sci USA 88:32003203.

Freidin M, Bennett MVL, Kessler JA (1992) Cultured sympathetic neurons synthesize and release the cytokine interleukin $1 \beta$. Proc Natl Acad Sci USA 89:10440-10443.

Fukada K (1985) Purification and partial characterization of a cholinergic neuronal differentiation factor. Proc Natl Acad Sci USA 82: 8795-8799.

Giulian D, Baker TJ (1985) Peptides released by ameboid microglia regulate astroglial proliferation. J Cell Biol 101:2411-2415.

Giulian D, Ingeman JE (1988) Colony-stimulating factors as promoters of ameboid microglia. J Neurosci 8:4707-4717.

Giulian D, Lachman LB (1985) Interleukin-1 stimulates astroglial proliferation after brain injury. Science 228:497-499.

Giulian D, Baker TJ, Shih LN, Lachman LB (1986) Interleukin-1 of the central nervous system is produced by ameboid microglia. J Exp Med 164:594-604.

Hannum CH, Wilcox CJ, Arend WP, Joslin FG, Dripps DJ, Heimdal PL, Armes LG, Sommer A, Eisenberg SP, Thompson RC (1990) Interleukin-1 receptor antagonist activity of a human interleukin-1 inhibitor. Nature 343:336-340.

Hart RP, Shadiack AM, Jonakait GM (1991a) Substance P gene expression is regulated by interleukin- 1 in cultured sympathetic ganglia. J Neurosci Res 29:282-291. 
Hart RP, Yang R, Riley LA, Green TL (1991b) Post-transcriptional control of tryptophan hydroxylase gene expression in rat brainstem and pineal gland. Mol Cell Neurosci 2:71-77.

Hart RP, Liu C, Shadiack AM, McCormack RJ, Jonakait GM (1993) Interleukin-I receptor type I mRNA is induced in cultured rat sympathetic ganglia. J Neuroimmunol 44:49-56.

Hetier E, Ayala J, Denefle P, Bousseau A, Rouget P, Mallat M, Prochiantz A (1988) Brain macrophages synthesize interleukin-1 and interleukin-1 mRNAs in vitro. J Neurosci Res 21:391-397.

Johnson M, Ross D, Meyers M, Rees R, Bunge R, Wakshull E, Burton H (1976) Synaptic vesicle cytochemistry changes when cultured sympathetic neurons develop cholinergic interactions. Nature 262 : 308-310.

Jonakait GM, Black IB (1989) Regulation of catecholamine development. In: Handbook of experimental pharmacology (Trendelenburg U, Weiner N, eds), pp 137-179. Berlin: Springer.

Jonakait GM, Schotland S (1990) Conditioned medium from activated splenocytes increases substance $P$ in sympathetic ganglia. $J$ Neurosci Res 26:24-30.

Jonakait GM, Schotland S, Hart RP (1990) Interleukin-1 specifically increases substance $P$ in injured sympathetic ganglia. In: Neuropeptides and immunopeptides: messengers in a neuroimmune axis (O'Dorisio MS, Panerai A, eds), pp 222-230. New York: New York Academy of Sciences.

Kamegai M, Niijima K, Kunishita T, Nishizawa M, Ogawa M, Araki M, Ueki A, Konishi Y, Tabira T (1990) Interleukin 3 as a trophic factor for central cholinergic neurons in vitro and in vivo. Neuron 2:429-436.

Kessler JA (1984) Non-neuronal cell conditioned medium stimulates peptidergic expression in sympathetic and sensory neurons in vitro. Dev Biol 106:61-69.

Kessler JA, Black IB (1982) Regulation of substance P in adult rat sympathetic ganglia. Brain Res 234:182-187.

Kessler JA, Freidin M (1991) Effects of D-factor on substance P expression in sympathetic neurons. Soc Neurosci Abstr 17:224.

Kessler JA, Adler JE, Bohn MC, Black IB (1981) Substance P in principal sympathetic neurons: regulation by impulse activity. Science 214:335-336

Kurkowski R, Kummer W, Heym C (1990) Substance P-immunoreactive nerve fibers in tracheobronchial lymph nodes of the guinea pig: origin, ultrastructure and coexistence with other peptides. Peptides $11: 13-20$.

Larsson J, Ekblom A, Henriksson K, Lundeberg T, Theodorsson E (1989) Immunoreactive tachykinins, calcitonin gene-related peptide and neuropeptide $Y$ in human synovial fluid from inflamed knee joints. Neurosci Lett 100:326-330.

Lindholm D, Heumann R, Meyer M, Thoenen H (1987) Interleukin-1 regulates synthesis of nerve growth factor in non-neuronal cells of rat sciatic nerve. Nature 330:658-659.

Maddens KS, Livnat KD, Ackerman S, Felten SY, Felten DL (1989) Patterns of noradrenergic innervation of lymphoid organs and immunological consequences of denervation. In: Neuroimmune networks: physiology and diseases (Goetzl EJ, Spector NH, eds), pp 18. New York: Liss.

Mantyh PW, Johnson DJ, Bochmer CG, Catton MD, Vinters HV, Maggio JE, Too HP, Vigna SR (1989) Substance $P$ receptor binding sites are expressed by glia in vivo after neuronal injury. Proc Natl Acad Sci USA 86:5193-5197.

Marriott DR, Wilkin GP, Wood JN (1991) Substance P-induced release of prostaglandins from astrocytes: regional specialisation and correlation with phosphoinositol metabolism. J Neurochem 56:259265.

Martinez HJ, Dreyfus CF, Jonakait GM, Black IB (1985) Nerve growth factor promotes cholinergic development in brain striatal cultures. Proc Natl Acad Sci USA 82:7777-7781.

Matsuda H, Kawakita K, Kiso Y, Nakano T, Kitamura Y (1989) Substance $P$ induces granulocyte infiltration through degranulation of mast cells. J Immunol 142:927-931

Moore TC, Lami JL, Spruck CH (1989) Substance P increases lymphocyte traffic and lymph flow through peripheral lymph nodes of sheep. Immunology 67:109-114.

Muscettola M, Grasso G (1990) Neuropeptide modulation of interferon gamma production. Int J Neurosci 51:189-191.
Nawa H, Patterson PH (1990) Separation and partial characterization of neuropeptide-inducing factors in heart cell conditioned medium. Neuron 4:269-277.

Nawa H, Sah DWY (1990) Different biological activities in conditioned media control the expression of a variety of neuropeptides in cultured sympathetic neurons. Neuron 4:279-287.

Nonaka M, Huang Z-M (1990) Interleukin-1-mcdiated enhancement of mouse factor $B$ gene expression via NF-kB-like hepatoma nuclear factor. Mol Cell Biol 10:6283-6289.

Nudel U, Zakut R, Shani M, Neuman S, Levy Z, Yaffe D (1983) The nucleotide sequence of the rat cytoplasmic beta-actin gene. Nucleic Acids Res 11:1759-1771.

Osborn L, Kunkel S, Nabel G (1989) Tumor necrosis factor $\alpha$ and interleukin 1 stimulate the human immunodeficiency virus enhancer by activation of the nuclear factor kB. Proc Natl Acad Sci USA 86: 2336-2340.

Patterson PH, Chun LLY (1977) The induction of acetylcholine synthesis in primary cultures of dissociated rat sympathetic neurons. I. Effects of conditioned medium. Dev Biol 56:263-280.

Payan DG, Brewster DR, Goetzl EJ (1983) Specific stimulation of human T lymphocytes by substance P. J Immunol 131:1613-1615.

Popper P, Mantyh CR, Vigna SR, Maggio JE, Mantyh PW (1988) The localization of sensory nerve fibers and receptor binding sites for sensory neuropeptides in canine mesenteric lymph nodes. Peptides 9:257-267.

Ramcshwar P, Gascon P, Ganea D (1992) Immunoregulatory effects of neuropeptides: stimulation of IL-2 production by substance $P$. J Neuroimmunol 37:65-74

Rao MS, Tyrrell S, Landis SC, Patterson PH (1992) Effects of ciliary neurotrophic factor (CNTF) and depolarization on neuropeptide ex pression in cultured sympathetic neurons. Dev Biol 150:281-293.

Reder AT, Karaszewski JW, Amason BGW (1989) Sympathetic nervous system involvement in immune responses of mice and in patients with multiple sclerosis. In: Ncuroimmune networks: physiology and disease (Goetzl EJ, Spector NH, eds), pp 137-147. New York: Liss.

Roach A, Adler JE, Black IB (1987) Depolarizing influences regulate preprotachykinin mRNA in sympathetic neurons. Proc Natl Acad Sci USA 84:5078-5081.

Role LW (1984) Substance P modulation of acetylcholine-induced currents in embryonic chicken sympathetic and ciliary ganglion neurons. Proc Natl Acad Sci USA 81:2924-2928.

Rougon G, Noble M, Mudge AW (1983) Neuropeptides modulate the $\beta$-adrenergic response of purified astrocytes in vitro. Nature 305:715716.

Saneto RP, Altman A, Knobler RL, Johnson HM, de Vellis J (1986) Interleukin 2 mediates the inhibition of oligodendrocytes progenitor cell proliferation in vitro. Proc Natl Acad Sci USA 83:9221-9225.

Scarborough DE, Lce SL, Dinarello CA, Reichlin S (1989) Interleukin$1 \beta$ stimulates somatostatin biosynthesis in primary cultures of fetal rat brain. Endocrinology 124:549-551.

Schultzberg M, Svenson SB, Inden A, Bartfai T (1987) Interleukin1-like immunoreactivity in peripheral tissues. J Neurosci Res 18:184 189

Stahl J, Gearing DP, Wilson T (1990) Structural organization of the genes for murine and human leukemia inhibitory factor. Evolutionary conservation of coding and non-coding regions. J Biol Chem 265: 8833-8841.

Stanisz AM, Befus D, Bienenstock J (1986) Differential effects of vasoactive intestinal peptide, substance $P$ and somatostatin on immunoglobulin synthesis and proliferation by lymphocytes from Peyer's patches, mesenteric lymph nodes and spleen. J Immunol 136:152156.

Sun Y, Rao MS, Landis SC, Zigmond RE (1992) Depolarization increases vasoactive intestinal peptide- and substance P-like immunoreactivities in cultured neonatal and adult sympathetic neurons. J Neurosci 12:3717-3728.

Tedeschi B, Barett JN, Keane RW (1986) Astrocytes produce interferon that enhances the expression of $\mathrm{H}-2$ antigens on a subpopulation of brain cells. J Cell Biol 102:2244-2253.

Torrens Y, Daguet De Montety MC, El Etr M, Beaujouan JC, Glowinski J (1989) Tachykinin receptors of the NKI type (substance P) coupled positively to phospholipase $C$ on cortical astrocytes from the newborn mouse in primary culture. $\mathrm{J}$ Neurochem 52:1913-1918. 
Weihe E, Muller S, Fink T, Zentel HJ (1989) Tachykinins, calcitonin gene-related peptide and neuropeptide $Y$ in nerves of the mammalian thymus: interactions with mast cells in autonomic and sensory neuroimmunomodulation? Neurosci Lett 100:77-82.

Wetzler M, Talpaz M, Lowe DG, Baiocchi G, Gutterman JU, Kurzrock R (1991) Constitutive expression of leukemia inhibitory factor RNA by human bone marrow stromal cells and modulation by IL-1, TNF$\alpha$, and TGF- $\beta$. Exp Hematol 19:347-351.

Yamamori T, Fukada K, Aebersold R, Korsching S, Fann M-J, Patterson PH (1990) The cholinergic neuronal differentiation factor from heart cells is identical to leukemia inhibitory factor. Science 246 : 1412-1416. 